\title{
Genome-wide survey of two-component signal transduction systems in the plant growth-promoting bacterium Azospirillum
}

\author{
Stéphanie Borland ${ }^{1}$, Anne Oudart ${ }^{2}$, Claire Prigent-Combaret ${ }^{1}$, Céline Brochier-Armanet ${ }^{2}$ \\ and Florence Wisniewski-Dyé ${ }^{*}$
}

\begin{abstract}
Background: Two-component systems (TCS) play critical roles in sensing and responding to environmental cues. Azospirillum is a plant growth-promoting rhizobacterium living in the rhizosphere of many important crops. Despite numerous studies about its plant beneficial properties, little is known about how the bacterium senses and responds to its rhizospheric environment. The availability of complete genome sequenced from four Azospirillum strains (A. brasilense Sp245 and CBG 497, A. lipoferum 4B and Azospirillum sp. B510) offers the opportunity to conduct a comprehensive comparative analysis of the TCS gene family.
\end{abstract}

Results: Azospirillum genomes harbour a very large number of genes encoding TCS, and are especially enriched in hybrid histidine kinases (HyHK) genes compared to other plant-associated bacteria of similar genome sizes. We gained further insight into HyHK structure and architecture, revealing an intriguing complexity of these systems. An unusual proportion of TCS genes were orphaned or in complex clusters, and a high proportion of predicted soluble HKs compared to other plant-associated bacteria are reported. Phylogenetic analyses of the transmitter and receiver domains of A. lipoferum 4B HyHK indicate that expansion of this family mainly arose through horizontal gene transfer but also through gene duplications all along the diversification of the Azospirillum genus. By performing a genome-wide comparison of TCS, we unraveled important 'genus-defining' and 'plant-specifying' TCS.

Conclusions: This study shed light on Azospirillum TCS which may confer important regulatory flexibility. Collectively, these findings highlight that Azospirillum genomes have broad potential for adaptation to fluctuating environments.

Keywords: Azospirillum, Hybrid histidine kinase, PGPR, Signal transduction, Two-component systems

\section{Background}

Plants live in intimate association with complex communities of microorganisms that fulfill important functions relative to plant growth and health [1]. These microorganisms can establish beneficial, neutral or detrimental associations of varying intimacy with their hosts. Plantassociated bacteria in the rhizosphere (i.e. the soil region strongly influenced by root activity), the phyllosphere (i.e. the aerial parts of plants dominated by the leaves) and endosphere (i.e. internal tissues) evolve in highly

\footnotetext{
* Correspondence: florence.wisniewski@univ-lyon1.fr

'Université de Lyon, Université Lyon 1, CNRS, UMR5557, Laboratoire d'Ecologie Microbienne, 437 boulevard du 11 novembre 1918, F-69622 Villeurbanne, France

Full list of author information is available at the end of the article
}

heterogeneous habitats, influenced by plant activity, variation of physicochemical factors and other microbial activities [2]. Therefore, the need to cope with various conditions and the ability to respond to environmental stimuli is essential for plant-associated bacteria.

Two component systems (TCS) are one of the primary means used by bacteria to sense and adjust their behaviour accordingly. They play important roles in a broad range of adaptive mechanisms such as virulence, chemotaxis, metabolism, motility, etc. [3]. The TCS signalling pathway relies on a phosphotransfer reaction between two proteins, a generally membrane-bound histidine kinase $(\mathrm{HK})$, characterized by the presence of a HisKA (PF00512) and a HATPase domain (PF02518), and 
a response regulator (RR) containing a REC domain (PF00072). In the most basic scheme, upon detection of a signal on the $\mathrm{N}$-terminal variable region containing the input domain, the HK autophosphorylates on a conserved histidine residue and subsequently transfers the phosphoryl group to a conserved aspartyl residue at the receiver domain (REC) of the RR. Phosphorylation of the RR leads to activation of the downstream output domain that elicits specific responses. More complex versions of TCS exist, called hybrid HKs (HyHK), with HK fused to REC, allowing multiple intramolecular phosphotransfer reactions or phosphorelays [4].

The growing number of complete prokaryotic genomes sequenced to date has dramatically improved our knowledge of TCS prevalence among bacteria. The number of TCS genes within an organism varies greatly and a strong relationship between bacterial ecological niche and sophistication of organism behaviour has been highlighted $[5,6]$. In plant pathogens where the TCS gene repertoire has been well studied, their number varies from 46 in Erwinia amylovora Ea1189 to 124 in Pseudomonas syringae (3 strains of various pathovars) [7, 8]. Nonetheless, despite extensive knowledge on TCS genes, still very little is known about these systems in beneficial plantassociated bacteria.

The alphaproteobacterium Azospirillum is a plant growth-promoting bacteria (PGPR) living in the rhizosphere of numerous plants such as crops and grasses $[9,10]$. Successful interaction with its host plant includes root colonization (motility, chemotaxis, and biofilm formation), phytohormone production, nitrogen fixation, modulation of plant hormonal balance, etc. Although several essential mechanisms underlying its positive association with plants have been elucidated, their utilization at the field-scale has been hampered by its inconstancy in terms of plant yields [11]. Indeed, Azospirillum are found associated with a large range of host plants, and have been isolated from many soil types under distinct geographic locations. Differential varietal response upon Azospirillum inoculation has been reported for several crops strongly suggesting the existence of host specificity $[12,13]$. Recently, with the availability of genomic sequences of four different Azospirillum strains, comparative genomic analyses have been implemented $[14,15]$. However the functions of a large proportion of their genes remain largely unknown [14, 15].

In this work, we focused on the analysis of Azospirillum TCS repertoire. We assessed their distribution among the four strains and unveiled the prevalence of this multigenic family among this genus, especially when considering HyHKs. We further gained insight into the structure and architecture of $\mathrm{HyHKs}$, revealing an intriguing complexity of these systems. Phylogenetic analyses of A. lipoferum 4B HyHKs underlined the importance of horizontal gene transfer and gene duplication events in the expansion of these HyHKs in this strain. Finally, we highlighted TCS potentially involved in host plant specificity.

\section{Methods}

\section{Data collection and sequence information}

TCS protein sequences were retrieved from the MaGe genome annotation platform (https://www.genoscope.cns.fr/ agc/microscope/home/index.php) for Azospirillum strains and from the P2CS database (http://p2cs.org/) for other strains [16, 17]. Detailed survey of Azospirillum TCS using P2CS was done on three complete genomes of Azospirillum: A. lipoferum 4B, Azospirillum sp. B510 and A. brasilense Sp245. For the fourth genome A. brasilense CBG497 (that can be accessed at the following link: https://www.genoscope.cns.fr/agc/microscope/home/index.php), the analysis was carried out manually following the P2CS pipeline to allow accurate comparisons between the four strains studied [17].

\section{Identification of TCS genes}

All TCS retrieved were further classified as HK, RR or phosphotransfer protein (i.e. presence of HisKA or Hpt domain -PF01627- and absence of REC or HATPase domain). Additionally, HKs were classified as classic or hybrid according to the presence of a REC domain within the protein. TCS classified by P2CS as 'Mispredicted' were included in our study and those classified as 'Incomplete HK' were manually validated based on the following criteria: (i) the presence of both HisKA domain (containing the His residue or H-box) and HATPase; (ii) exceptions were made for HKs whose transmitter region was composed solely of a HisKA domain but if its gene was adjacent to that encoding another TCS gene. Finally, all the identified putative TCS were manually curated to avoid false-positive and false-negative results.

\section{Comparison of TCS content among plant-associated bacteria}

To compare Azospirillum TCS genes with plant-associated bacteria, proteomes of plant-associated bacteria were selected among those available in P2CS database in September 2014. As very few intraspecies differences in TCS gene content were found, one representative of each species was selected in this study, i.e. 85 proteomes. They included 34 PGPR (i.e. free-living beneficial bacteria including non-obligatory endophytes), 25 symbionts (i.e. obligatory endophytes and root-nodulating bacteria) and 26 phytopathogens (i.e. causing plant diseases) (Additional file 1: Table S1). Eight genomes of non-plant-associated bacteria were also included, i.e. those of the model bacteria, Bacillus subtilis subsp. 
subtilis str. 168, Escherichia coli K-12, Myxoccocus xanthus DK 1622, a species whose TCS gene repertoire is well documented [18] and five genomes of bacteria belonging to the Rhodospirillaceae family (two Magnetospirillum and three Rhodospirillum strains), that are the closest Azospirillum relatives [14].

\section{Detection of orthologous TCS}

In order to identify orthologous proteins, a best reciprocal BLASTP analysis was performed using each TCS protein of the four Azospirillum strains as seed and the four corresponding proteomes as target as previously described [15]. The following parameters were considered: amino acid identity percentage greater than $35 \%$ and query coverage greater than $75 \%$. To confirm the results obtained with reciprocal BLAST, we used the protein sequence clustering program CD-HIT at $35 \%$ sequence identity level [19].

\section{Phylogenetic analysis}

A phylogenetic tree showing the relatedness of the different 97 organisms (85 plant-associated bacteria +3 model species +5 close relatives of Azospirillum +4 Azospirillum strains) discussed below has been constructed using ten ribosomal proteins (L3, L5, L11, L13, L14, S3, S7, S9, S11, and S17). The protein sequences were aligned with Clustal $\Omega$ [20]. Resulting multiples alignments were visually inspected using SEAVIEW 4.5.4., then trimmed using the Gblocks program with default parameters and finally concatenated [21, 22]. A distance-based method phylogenetic tree was inferred by the neighbor-joining method using the Poisson correction. The robustness of the tree was evaluated by the non-parametric bootstrap procedure implemented in SeaView (1,000 replicates of the original dataset).

A local database gathering 2775 prokaryotic complete proteomes available in November 2014 at the NCBI (http://www.ncbi.nlm.nih.gov/) was built and formatted with the FORMATDB program of the BLAST package (version 2.2.26) [23]. This database contained archaeal and bacterial proteomes, including that of three Azospirillum strains (A. brasilense Sp245, A. lipoferum 4B and Azospirillum sp. B510). The proteome of $A$. brasilense CBG497 (6,185 protein sequences) was retrieved from MaGe [16] and added to the local database. The protein sequences of the $49 \mathrm{HK}$ and the 62 REC domains contained in the 49 HyHKs from A. lipoferum 4B were used as queries for similarity search. For each domain sequence, the 100 most similar homologues were identified using BLASTP, with the default parameters, except the filter on low complexity regions that was turned off. The sequences were retrieved and the corresponding 111 datasets were aligned with MAFFT v7.123b [24] with the L-INS-i option. The resulting multiple alignments were trimmed with the Gblocks program [21] implemented in the SeaView 4.5.4 software [22], allowing smaller final blocks and less strict flanking positions. Maximum likelihood (ML) phylogenetic trees corresponding to the 111 cleaned alignments were inferred with PHYML-3.1 [25]. We used the Le and Gascuel model [26], with a gamma distribution in order to take into account evolutionary rate variations across sites (4 relative substitution rates), and the $\mathrm{NNI}+\mathrm{SPR}$ topology search strategy. The alpha parameter of the gamma distribution was estimated with PHYML. The robustness of the branches of the resulting ML trees was estimated with the Shimodaira-Hasegawa-like procedure implemented in PHYML. A similar procedure was used to infer the phylogeny of the 49 and that of the $62 \mathrm{~A}$. lipoferum HK and REC domains, respectively.

\section{Results \& discussion}

\section{Enrichment of TCS genes in Azospirillum compared to} other plant-associated bacteria

General features of Azospirillum TCS proteins retrieved from the P2CS database and the Mage platform are summarized in Table 1. The complete genomes chosen for this analysis include those of: (i) Azospirillum sp. B510, a strain isolated from disinfected rice stems in Japan [27], (ii) A. lipoferum 4B isolated from rice in France, (iii) A. brasilense Sp245 isolated from wheat in Brazil [14], and (iv) A. brasilense CBG497, isolated from maize grown on an alkaline soil ( $\mathrm{pH} 8)$ in Mexico [15]. First, Azospirillum devotes between 3.3 \% (A. brasilense Sp245) to $3.9 \%$ (A. lipoferum 4B) of its genes to TCS ORFs. Indeed, A. lipoferum 4B possesses a total of 244 putative TCS genes out of 6,233 ORFs, comprising 118 genes encoding HKs (69 classic HKs and 49 HyHKs) and 121 RRs. Azospirillum sp. B510, the closest relative of $A$. lipoferum (Additional file 2: Figure S1), has 260 TCS genes, 122 HKs (75 classic HKs and 47 HyHKs) and 132 RRs. Moreover, no phosphotransfer protein (i.e. standalone HisKA or Hpt domain-containing protein) has been detected in A. lipoferum 4B and in Azospirillum sp. B510 genomes. However Hpt domain detection has often been hampered by low sequence conservation, thus, Azospirillum genomes may encode more proteins containing $\mathrm{Hpt}$ domains than detected in our study [28]. A. brasilense Sp245 possesses a total of 259 TCS genes, $129 \mathrm{HKs}$ (74 classic HKs and $55 \mathrm{HyHKs}$ ), 124 RRs and 2 phosphotransfer proteins ( $2 \mathrm{Hpt})$. Finally, A. brasilense CBG497 has a total of 227 putative TCS genes encompassing 110 HKs (60 classic HKs and $50 \mathrm{HyHKs}), 111 \mathrm{RRs}$ and two phosphotransfer proteins ( $1 \mathrm{HisKA}$ and $1 \mathrm{Hpt}$ ). CheA gene numbers retrieved in this study are in accordance with previous Azospirillum whole-genome analyses [14, 15]. As the Che systems have been previously described elsewhere, we chose to specifically focus on TCS proteins 
Table 1 General features of Azospirillum TCS genes

\begin{tabular}{|c|c|c|c|c|c|c|c|c|c|}
\hline Strains and feature & TCS type & Chromosome & $\mathrm{p} 1$ & $\mathrm{p} 2$ & $\mathrm{p} 3$ & $\mathrm{p} 4$ & $\mathrm{p} 5^{\mathrm{a}}$ & p6 & Total $^{b}$ \\
\hline \multicolumn{10}{|l|}{ A. lipoferum 4B } \\
\hline \multirow[t]{3}{*}{ Sensing HK } & Classic HK & 34 & 8 & 11 & 6 & 4 & 6 & - & 69 \\
\hline & Hybrid HK & 18 & 5 & 5 & 3 & 11 & 5 & 2 & 49 \\
\hline & CheA & 2 & - & 1 & - & 2 & - & - & 5 \\
\hline Output response & RR & 61 & 9 & 18 & 9 & 15 & 9 & - & 121 \\
\hline \multirow[t]{2}{*}{ Phosphotransfer } & HisKA & - & - & - & - & - & - & - & - \\
\hline & Hpt & - & - & - & - & - & - & - & - \\
\hline Total & & 115 & 22 & 35 & 18 & 32 & 20 & 2 & 244 \\
\hline ORF & & 2904 & 883 & 640 & 555 & 599 & 415 & 237 & 6233 \\
\hline Size (Mpb) & & 2.99 & 1.04 & 0.75 & 0.65 & 0.65 & 0.48 & 0.29 & 6.85 \\
\hline \multicolumn{10}{|l|}{ Azospirillum sp. B510 } \\
\hline \multirow[t]{3}{*}{ Sensing HK } & Classic HK & 31 & 13 & 6 & 10 & 4 & 11 & - & 75 \\
\hline & HyHK & 22 & 9 & 1 & 3 & 8 & 4 & - & 47 \\
\hline & CheA & 2 & 2 & - & - & 2 & - & - & 6 \\
\hline Output response & RR & 60 & 23 & 7 & 13 & 15 & 14 & - & 132 \\
\hline \multirow[t]{2}{*}{ Phosphotransfer } & HisKA & - & - & - & - & - & - & - & - \\
\hline & Hpt & - & - & - & - & - & - & - & - \\
\hline Total & & 115 & 47 & 14 & 26 & 29 & 29 & & 260 \\
\hline ORF & & 3287 & 1263 & 693 & 589 & 598 & 464 & 232 & 7126 \\
\hline Size (Mpb) & & 3.31 & 1.46 & 0.72 & 0.68 & 0.63 & 0.54 & 0.26 & 7.60 \\
\hline \multicolumn{10}{|l|}{ A. brasilense Sp245 } \\
\hline \multirow[t]{3}{*}{ Sensing HK } & Classic HK & 31 & 22 & 8 & 5 & 7 & 1 & - & 74 \\
\hline & HyHK & 19 & 13 & 6 & 9 & 7 & 1 & - & 55 \\
\hline & CheA & 1 & 2 & 1 & - & - & - & - & 4 \\
\hline Output response & RR & 47 & 37 & 19 & 9 & 11 & 1 & - & 124 \\
\hline \multirow[t]{2}{*}{ Phosphotransfer } & HisKA & - & - & - & - & - & - & - & 0 \\
\hline & Hpt & 1 & 1 & - & - & - & - & - & 2 \\
\hline Total & & 99 & 75 & 34 & 23 & 25 & 3 & - & 259 \\
\hline ORF & & 3309 & 1812 & 922 & 824 & 691 & 163 & 125 & 7846 \\
\hline Size (Mpb) & & 3.02 & 1.77 & 0.91 & 0.78 & 0.69 & 0.19 & 0.17 & 7.53 \\
\hline \multicolumn{10}{|l|}{ A. brasilense CBG497 } \\
\hline \multirow[t]{3}{*}{ Sensing HK } & Classic HK & 26 & 17 & 9 & 4 & 4 & - & - & 60 \\
\hline & HyHK & 21 & 14 & 7 & 2 & 6 & - & - & 50 \\
\hline & CheA & 1 & 2 & 1 & - & - & - & - & 4 \\
\hline Output response & $\mathrm{RR}$ & 47 & 32 & 20 & 5 & 7 & - & - & 111 \\
\hline \multirow[t]{2}{*}{ Phosphotransfer } & HisKA & 1 & - & - & - & - & - & - & 1 \\
\hline & Hpt & - & 1 & - & - & - & - & - & 1 \\
\hline Total & & 96 & 66 & 37 & 11 & 17 & - & - & 227 \\
\hline ORF & & 2895 & 1430 & 643 & 512 & 583 & - & 122 & 6185 \\
\hline Size (Mpb) & & 2.90 & 1.60 & 0.73 & 0.49 & 0.60 & - & 0.15 & 6.47 \\
\hline
\end{tabular}

absent in A. brasilense CBG497

${ }^{\mathrm{b}}$ For each strain, the total number of TCS genes and genome size are highlighted in bold 
that are not part of Che-like systems. Analysis of the receiver (REC-containing domains RRs and HyHKs): transmitter (HisKA and HATPase-containing domains, HKs and HyHKs) values revealed a ratio closed to 1.4, thus suggesting that one HK may phosphorylate more than one RR.

The number of TCS per genome is positively correlated with genome size $[5,6]$. This number appears to correlate strongly with ecological niche, as bacteria living in relatively constant environments tend to have few TCS and contrarily, free-living bacteria experiencing fluctuating environmental conditions, or having complex physiological behaviours tend to be enriched in TCS genes $[29,30]$. Thus, to provide a suitable context for our comparisons, we selected 85 complete prokaryotic genomes from bacteria living in close association with plants and experiencing contrasting plant-associated lifestyles (i.e. 34 free-living bacteria or PGPR, 25 symbionts, 26 plant pathogens) and compared their TCS gene repertoire with those retrieved in Azospirillum (Additional file 3: Table S2; Additional file 4: Table S3; Additional file 5: Table S4 and Additional file 6: Table S5). We also included eight other genomes in our dataset, i.e. those of: (i) the two model bacteria, Escherichia coli K-12 and Bacillus subtilis subsp. subtilis str. 168, whose TCS have been extensively described [28, 31]; (ii) the deltaproteobacterium Myxococcus xanthus DK 1622 as a representative of large genome size organism $(9.14 \mathrm{Mpb})$, characterized by a complex social behaviour (fruiting body formation) and described as containing a very large number of TCS genes (i.e. 278) [18]; (iii) Magnetospirillum magneticum, Rhodospirillum centenum, $R$. photometricum and $R$. rubrum, free-living aquatic members of the Rhodospirillaceae family that are the closest Azospirillum relatives, as TCS gene content is also influenced by bacterial phylogeny $[14,32]$.

Our analysis demonstrated a positive correlation between TCS total gene number and genome size, which is in accordance with previous studies (Fig. 1a) $[5,6]$. More importantly, compared to other plant-associated bacteria with similar genome size, all four Azospirillum strains appeared to be enriched in TCS. Indeed, the genomes of the beneficial biocontrol fluorescent Pseudomonas protegens CHA0 (6.9 Mbp) and P. fluorescens SBW25 (7.1 Mbp) encode respectively 170 and 173 TCS genes, representing $2.8 \%$ and $2.9 \%$ of their ORFs; genomes of the nitrogen fixing symbionts of legumes, $R$ hizobium tropici CIAT 889 (6.7 Mpb), R. leguminosarum bv. trifolii WSM 1325 (7.4 Mpb) and Cupriavidus taiwanensis LMG19424 (6.5 Mpb), encode only respectively 112, 160 and 146 TCS genes (Fig. 1a; Additional file 1: Table S1). The only organisms displaying a number of TCS genes larger than that of Azospirillum are organisms with larger genomes. These organisms comprise the filamentous cyanobacterium Nostoc punctiforme PCC 73102 (9.2 Mp encoding 286 TCS genes) and M. xanthus DK 1622 (9.1 Mpb encoding 286 TCS genes), two bacteria capable of complex behaviors, such as cell differentiation and multicellular development (respectively heterocysts and fruiting bodies formation) $[5,18,33]$.
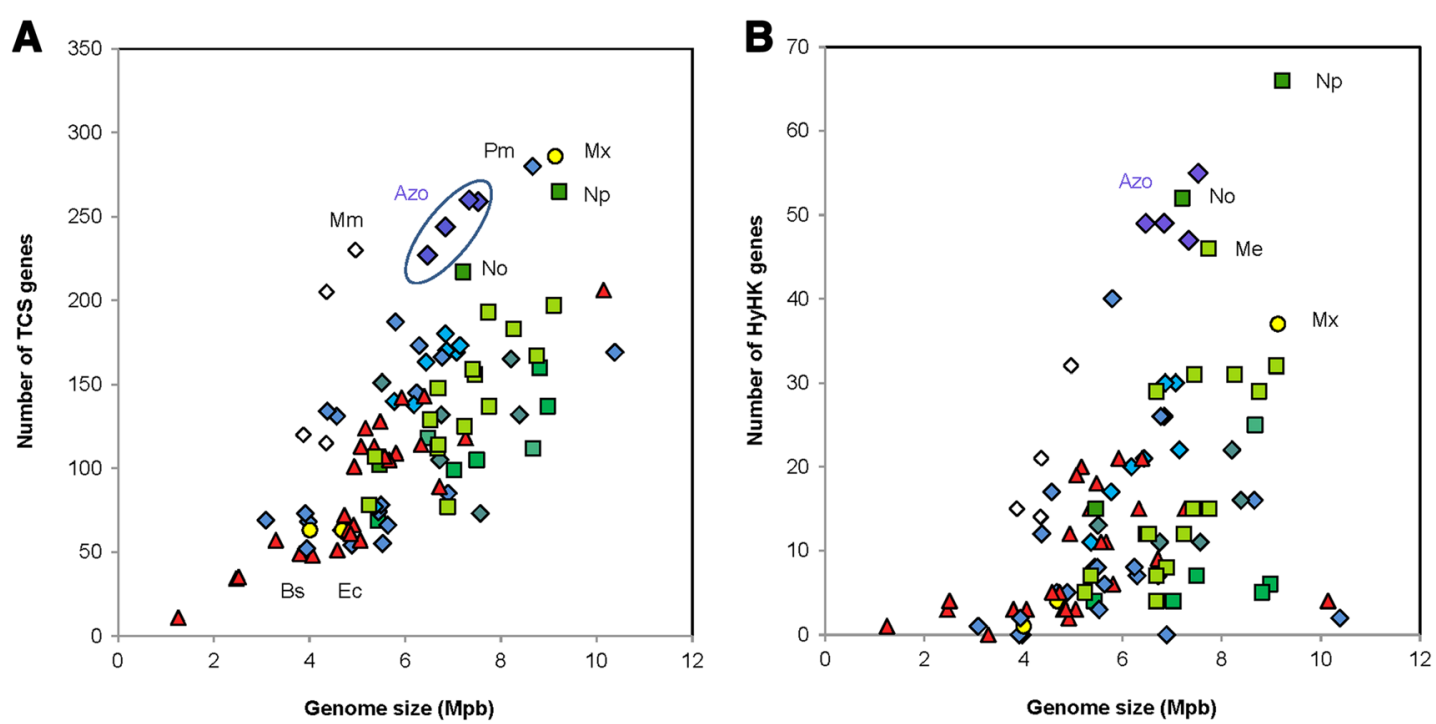

Fig. 1 Correlation between the number of TCS genes and genome size among plant-associated bacteria. a Number of all TCS genes. $\mathbf{b}$ Number of genes encoding HyHKs. Symbols represent, yellow circles: model organisms (B. subtilis, E. coli, M. xanthus); red triangles: phytopathogens; green squares: plant symbionts (light green for Rhizobia, medium green for Frankia and dark green for Nostoc); blue diamonds: PGPR; open diamonds: aquatic Rhodospirillaceae. Abbreviations are, Azo: Azospirillum; Bs: B. subtilis BSn5; Ec: E. coli K12; Me: Methylobacterium sp. 4-46; Mm: M. magneticum AMB-1; Mx: M. xanthus DK1622; No: Nostoc sp. PCC 7120; Np: N. punctiforme PCC 73102; Pm: Paenibacillus mucilaginosus KNP414 
Additionally, the nitrogen-fixing firmicute Paenibacillus mucilaginosus KNP414 was also found to possess many TCSs (8.6 Mpb encoding 280 TCS). This feature has previously been unveiled in one of its closest relatives Paenibacillus vortex, in which enrichment in TCS presumably correlated with its sophisticated social motility [34]. Although Azospirillum displays no complex cellular behaviours such as those described above, transformation of vegetative cells to desiccation-resistant encysting forms under limiting cultural conditions has been reported [35] and this process may necessitate the integration of a multitude of signals. As for the other Rhodospirillaceae, the magnetotactic alpha-proteobacterium M. magnetotaticum AMB-1 showed an unexpectedly high number of TCS, as high as that of Azospirillum despite a smaller genome (4.9 Mpb encoding 230 TCS genes) whereas the genome of Rhodospirillum centenum CW (4.3 $\mathrm{Mpb}$ ) encodes only $115 \mathrm{TCS}$. The presence of numerous signal transduction genes was shown to be a common feature in magnetotactic bacteria, enabling them to tightly adjust their physiology to adapt to varying environmental conditions [36]. This suggests that most TCS genes among the Rhodospirillaceae family have been acquired prior to speciation and thus lineage specific gene loss occurred among the Rhodospirillum genus (Additional file 2: Figure S1). However, our phylogenetic analysis of HyHK of A. lipoferum 4B (see below) contradicts this hypothesis.

\section{Abundance of orphaned and complex TCS genes in Azospirillum genomes}

TCS genetic organization is important information regarding potential TCS partnership as many genes encoded within the same operon function in the same pathway. In this regard, we classified Azospirillum TCS genes according to their genetic context as either (i) orphan when no TCS gene was found adjacent to another TCS gene, (ii) paired when two TCS genes, whatever their nature (HK or RR), were found adjacent and (iii) complex when more than two genes were contiguous [37]. The proportion of Azospirillum TCS genes that are paired varies from $36-43 \%$, whereas orphaned TCS genes account for 38-52 \% of TCS genes (Table 2). Besides, 15-18 \% of Azospirillum TCS genes are

Table 2 Genetic organization of Azospirillum TCS

\begin{tabular}{llllllll}
\hline Strain & Orphan & Pair & Triad & Tetrad & Pentad & Hexad & TOTAL \\
\hline A. lipoferum 4B & 106 & 48 & 5 & 4 & 1 & 1 & 244 \\
$\begin{array}{l}\text { Azospirillum sp. } \\
\text { B510 }\end{array}$ & 100 & 56 & 12 & 3 & 0 & 0 & 260 \\
$\begin{array}{l}\text { A. brasilense } \\
\text { Sp245 }\end{array}$ & 128 & 46 & 10 & 1 & 1 & 0 & 259 \\
$\begin{array}{l}\text { A. brasilense } \\
\text { CBG497 }\end{array}$ & 101 & 42 & 10 & 3 & 0 & 0 & 227 \\
\hline
\end{tabular}

organized in complex clusters. Nonetheless, these complex loci organization vary among the four strains, in terms of number and combination. The smallest replicon of A. lipoferum 4B (p6, 237 ORFs), the and only replicon that has the features of typical plasmids [14], harbours only two genes encoding orphan HyHK (AZOLI_p60219 and AZOLI_p60221) that display no orthologues in other Azospirillum genomes. Still in A. lipoferum 4B a hexad of TCS chromosomally-encoded genes is particularly intriguing, spanning from AZOLI_0973 to AZOLI_0978, with two classic HKs followed by four RRs (Additional file 3: Table S2). However, the putative phosphotransfer route deduced from this configuration is difficult to understand and would need further experimental investigation.

In comparison, the majority of E. coli TCS were organized as pairs $(71.5 \%)$, while orphaned and complex TCS accounted for respectively $14.5 \%$ and $14.5 \%$ [28]. In $M$. xanthus, only $29 \%$ TCS genes were found to be adjacent to each other, $33 \%$ of them formed complex clusters and $38 \%$ were categorized as orphans, a repartition resembling that found in Azospirillum [18]. Strikingly, a high number of $M$. magnetotaticum TCS genes were classified as orphans (63\%), while only $20 \%$ were found to lie adjacent to another TCS gene, and $17 \%$ were clustered in complex loci (data not shown).

The enrichment of non-conventional TCS genetic organization has been observed in bacterial species that have large genomes, thus supporting the idea that as genome size increases, communication among TCS proteins may be favored leading to complex signal transduction pathways [37, 38]. Altogether, this suggests that Azospirillum have evolved complex signalling transduction pathways that may allow a better adaptation to a given niche.

\section{Overrepresentation of HyHKs in Azospirillum}

As Azospirillum strains appeared to be enriched in TCS compared to other plant-associated bacteria of similar genome size, we next focused on HKs and RRs separately. For these two sets of proteins, the same general trend between abundance and genome size can be observed, with Azospirillum displaying elevated numbers of HKs and RRs for its genome size (Fig. $1 \mathrm{~b}$ and data not shown). Notwhistanding this observation, the relationship between the numbers of encoded HyHKs within our set of selected genomes of plant-associated bacteria, did not follow a linear relationship between these two parameters (Fig. 1b), as previously reported [39]. Surprisingly, Azospirillum genomes were found to contain a high number of HyHKs genes (49 to 55) compared to other plant-associated bacteria of similar genome size: $P$. protegens CHA0 (30 HyHKs), P. fluorescens SBW25 (22 HyHKs), $R$. tropici CIAT 899 (4 HyHKs), R. leguminosarum bv. 
trifolii WSM 1325 (16 HyHKs) and C. taiwanensis LMG19424 (12 HyHKs). Even more stunning is the fact that the number of HyHKs in Azospirillum overtakes the numbers found in bacteria with larger genomes (37 in $M$. xanthus DK 1622; 16 in P. mucilaginosus KNP414), with the only exception of two cyanobacterial strains (52 in Nostoc sp. PCC 7120 and 66 in N. punctiforme PCC 73102). HyHKs sensing proteins are involved in phosphorelays signalling cascades that may offer additional regulatory checkpoints allowing the fine-tuning of some physiological behaviours in response to given signals. Further evidence now supports some additional roles of HyHKs, such as mediating direct protein-protein interactions [40]. Therefore, HyHKs may play a pivotal role for rapid acclimation and fine-tuning of Azospirillum physiology in the soil and root environments.

The cellular localization of each HK was further assessed by the presence or absence of transmembrane helices (Additional 3: Table S2; Additional file 4: Table S3; Additional file 5: Table S4; and Additional file 6: Table S5). A mean of $39 \%( \pm 1 \%)$ of total Azospirillum HKs were predicted to contain no transmembrane segment, suggesting a cytosolic subcellular localization (Fig. 2). Previous genome analyses predicted that only $12-27 \%$ of HKs have no transmembrane regions, the maximum being reported for cyanobacteria and myxobacteria (50\% M. xanthus and $64 \% N$. punctiforme of cytosolic HKs) $[5,19]$. In other plant-associated bacteria, the proportion of soluble HKs were respectively 23, 23, $34 \%$ and $23 \%$ in P. protegens CHA0, P. fluorescens SBW25, Rhizobium leguminosarum bv. trifolii WSM1325 and in C. taiwanensis LMG 19424 strains (Fig. 2). By comparing the proportion of potentially soluble and membrane $\mathrm{HKs}$ between classic $\mathrm{HKs}$ and HyHKs in Azospirillum genomes, a slightly higher proportion of HyHKs were found to be soluble (mean of $42 \% \pm$ $1 \%$ ) compared to their classical counterparts (mean of $37 \% \pm 1 \%$ ), although not statistically significant (Fig. 2). Soluble sensing HKs were initially thought to sense intracellular cues (ATP, redox potential, reactive oxygen species) allowing the bacteria to monitor the internal metabolic status of a cell. However, membrane-diffusible signals could also be perceived by soluble HKs; consequently these systems could be relevant in the complex rhizosphere ecosystem, allowing the integration of a wide array of physicochemical parameters and plant-exuded compounds. Furthermore, the prevalence of cytosolic

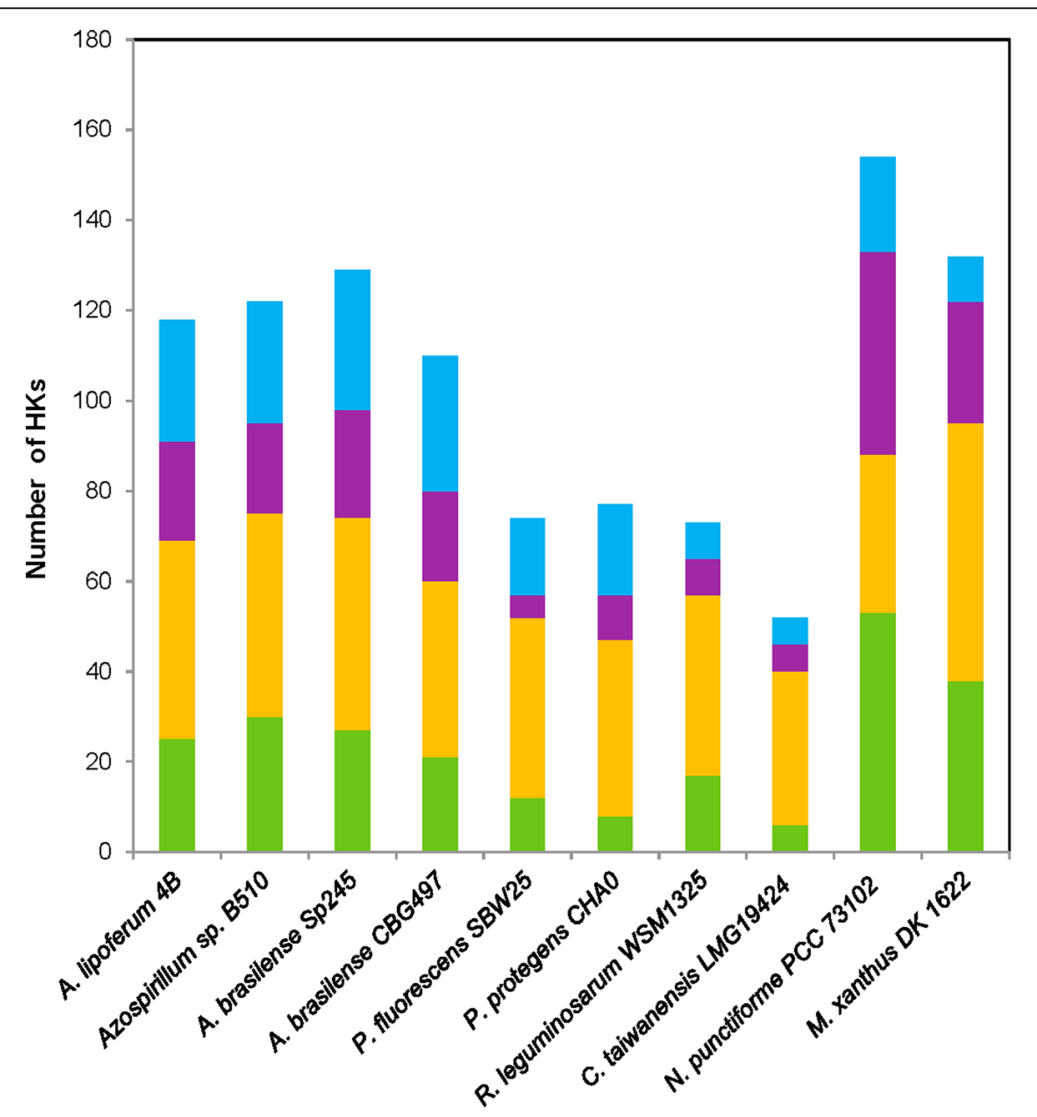

Fig. 2 Predicted subcellular localization of HKs from Azospirillum and other plant-associated bacteria. For each selected strain, the predicted subcellular localization of HKs was retrieved from the P2CS database or using the TMHMM server v. 2.0 for A. brasilense CBG497 HKs. Green: soluble classic HKs; orange: membrane classic HKs; purple: soluble HyHKs; blue: membrane HyHKs 
HyHKs within an organism could provide a selective advantage by favouring spatial proximity with its cognate $R R$, therefore increasing the velocity and efficiency of the phosphotransfer signalling route [41].

\section{Insight into domain architecture of Azospirillum HKs Sensing domains}

Analysis of sensing domains is crucial to understand the nature of the signals detected by individual HKs. A search for common and uncommon input domains described previously [42] was achieved among Azospirillum $\mathrm{HKs}$. Intriguingly, $\mathrm{HKs}$ without any input domain represent around $28 \%( \pm 0.35 \%)$, thus suggesting that they might contain either unknown domains, or that they may be part of more complex signalling systems, acting in concert with auxiliary proteins (Table 3; Additional 3: Table S2; Additional file 4: Table S3; Additional file 5: Table S4; and Additional file 6: Table S5) [43]. For HKs containing an input domain, a mean of $13( \pm 1.5)$ distinct sensing domains were identified among Azospirillum HKs, with A. lipoferum 4B and Azospirillum sp. B510 exhibiting a wider diversity of input domains than the A. brasilense strains (Table 3). By comparison, plant-associated bacteria with similar genome size contained a slightly lower diversity of input domains, from 9 (R. tropici CIAT899) to 12 (P. protegens CHA0). Finally, M. xanthus DK 1622 and N. punctiforme PCC 73102 were found to have respectively 14 and 11 distinct sensing domains among their HKs (data not shown).

A vast majority of input domain-containing HKs were found to contain a PAS (Per-Arnt-Sim) domain (Table 3; Additional 3: Table S2; Additional file 4: Table S3; Additional file 5: Table S4; and Additional file 6: Table S5) [44]. PAS domains have been shown to sense a wide array of intracellular and/or extracellular signals, such as small molecules, ions, light, gases, redox state [45]. PAS domains were found to be more abundant among HyHKs than among classic HKs; indeed, 43 PAS domains were distributed over 69 classic HKs whereas 42 of them were distributed over 49 HyHKs (Table 3). The HAMP domain (Histidine kinases, Adenylyl cyclases, Methyl binding proteins, Phosphatases) was found in $31 \%( \pm 2 \%)$ of input domain-containing HKs. This domain converts signals from periplasmic sensor domains to cytoplasmic output domains via conformational changes [46]. The GAF domain (cGMP-specific phosphodiesterases, Adenylyl cyclases and FhlA) was found in all Azospirillum strains but to a lesser extent $(10 \% \pm 1 \%$ of input domain-containing HKs). All four Azospirillum strains contain at least one photoreceptor PHY domain, displaying the $\mathrm{N}$-terminal domain arrangement reminiscent of bacterial phytochromes (PAS-GAF-PHY) (Table 3) [47]. The classical HK containing this PHY domain is a type 1 bacteriophytochrome (AZOLI_p20424, AZL_a05830, AZOBR_p440075

Table 3 Input domains found in Azospirillum sensing HKs

\begin{tabular}{|c|c|c|c|c|c|c|c|c|c|}
\hline \multirow{2}{*}{$\begin{array}{l}\text { Strains } \\
\text { HK type }^{a}\end{array}$} & \multicolumn{2}{|c|}{$\begin{array}{l}\text { A. lipoferum } \\
4 \mathrm{~B}\end{array}$} & \multicolumn{2}{|c|}{$\begin{array}{l}\text { Azospirillum } \\
\text { sp. B510 }\end{array}$} & \multicolumn{2}{|c|}{$\begin{array}{l}\text { A. brasilense } \\
\text { Sp245 }\end{array}$} & \multicolumn{2}{|c|}{$\begin{array}{l}\text { A. brasilense } \\
\text { CBG497 }\end{array}$} & \multirow[t]{2}{*}{ Putative signal(s) detected } \\
\hline & ClaHK & HyHK & ClaHK & HyHK & ClaHK & HyHK & ClaHK & HyHK & \\
\hline \multicolumn{10}{|c|}{ Abundant input domains } \\
\hline $\mathrm{PAS} / \mathrm{PAC}$ & 43 & $42 / 1$ & 35 & $35 / 3$ & 46 & 71 & 35 & 71 & Small molecules, ions, gases, light, and redox state sensing \\
\hline HAMP & 12 & 18 & 18 & 9 & 14 & 11 & 11 & 13 & Signal transduction \\
\hline \multicolumn{10}{|c|}{ Uncommon input domains } \\
\hline GAF & 3 & 4 & 3 & 4 & 7 & 4 & 5 & 4 & Redox or oxygen sensing; cGMP binding \\
\hline $\mathrm{PHY}$ & 1 & - & 1 & 1 & 1 & 1 & 1 & 1 & Tetrapyrroles; light-sensing \\
\hline CHASE & 3 & - & 2 & - & 3 & - & 2 & - & Small molecules recognition \\
\hline MASE & 1 & 1 & 2 & - & 1 & - & 1 & 1 & Membrane associated sensor \\
\hline 2CSK_N & 1 & - & 3 & - & 1 & - & 1 & - & Unknown; commonly found in N-terminal parts of HK \\
\hline Cache & - & 4 & - & 4 & 2 & 3 & - & - & Small molecules recognition \\
\hline MHYT & - & 2 & - & 3 & - & - & - & 2 & Putatively involved in metal sensing \\
\hline cNMP_binding & 1 & - & 1 & - & - & - & - & - & Cyclic nucleotide monophosphate-binding \\
\hline S_TKC & 1 & - & 1 & - & - & - & - & - & Serine/Threonine kinase catalytic domain \\
\hline SBP_bac_1 & 1 & - & 1 & - & - & - & 1 & - & Bacterial extracellular solute binding protein \\
\hline CheB methylesterase & - & - & 1 & 2 & - & - & - & - & Chemotaxis \\
\hline MeTRC & - & - & 1 & 2 & - & - & - & - & Methyl transferase \\
\hline NIT & - & - & 1 & - & - & - & - & - & Nitrate and nitrite responsive \\
\hline $\mathrm{PBPb}$ & - & - & - & - & 1 & - & 1 & - & High-affinity periplasmic solute-binding protein \\
\hline
\end{tabular}


and AZCBG_p440017). In A. brasilense Sp7, this protein was shown to be involved in tolerating red light mediated photodynamic stress, and was further shown to be involved in the regulation of swarming motility [48].

Some sensing domains were found to be absent in the two A. brasilense strains but present in A. lipoferum 4B and Azospirillum sp. B510, such as cNMP binding domain (PF00027) and S_TK (PF00069), that are respectively involved in cyclic nucleotide monophosphate binding detection and crosstalk between Ser/Thr signalling process. Conversely, one $\mathrm{PBPb}$ (Periplasmic solute-Binding Protein) domain (PF12974) was found associated only with the two A. brasilense strains (AZOBR_p230031 and AZCBG_p2110061). Bacterial periplasmic solute-binding proteins often function as receptors regulating chemotaxis, transport systems and/or signal transduction pathways [49]. Furthermore, some sensing domains were found exclusively in association with a particular Azospirillum strain. This is the case for the NIT (Nitrate- and nitrite- sensing) domain (PF08376) that was found only in a single Azospirillum sp. B510 classic HK (AZL_012680). Its association with two other PAS domains suggests that it could detect change in nitrate or nitrite concentration [50]. However, the exact roles of these sensing domains are difficult to apprehend, as for most functionally characterized HKs, the signal(s) detected are still unknown.
Altogether, it seems that Azospirillum strains have evolved a multitude of sensing strategies that may favor adaptation to particular ecological niches.

\section{Architectures of Azospirillum HK}

Domain architecture has been proven to be very informative regarding the putative function of signalling proteins [51]. Analysis of HK domain arrangement in Azospirillum showed a wide array of domain combinations among HyHKs compared to their classical counterparts (Table 4; Additional 3: Table S2; Additional file 4: Table S3; Additional file 5: Table S4; and Additional file 6: Table S5). Indeed, when HKs were classified according to the number and order of their input domains (whatever the nature of the sensing domain), transmitter (comprising HisKA and HATPase domains) and receiver domains, only six distinct domain architecture combinations could be found among Azospirillum classical HKs (data not shown). On the contrary, a remarkable diversity of domain architectures was observed when considering HyHKs (respectively 19, 19, 16, 13 distinct domain architectures in A. lipoferum 4B, Azospirillum sp. B510, A. brasilense Sp245 and CBG497) (Table 4). Firstly, HyHKs composed of only one transmitter and one receiver domain constitute the majority of HyHK domain architectures found in Azospirillum genomes (67 $\pm 2 \%$ ),

Table 4 Schematic representation of HK domain architecture and occurrence among Azospirillum genomes

\begin{tabular}{|c|c|c|c|c|}
\hline \multirow{2}{*}{ Domain architecture * } & \multicolumn{4}{|c|}{ Occurrence ${ }^{+}$} \\
\hline & 4B & B510 & Sp245 & CBG497 \\
\hline$-r$ & $9(3)$ & $9(1)$ & $8(2)$ & $7(4)$ \\
\hline$\rightarrow$ & 3 & 3 & $4(1)$ & $2(2)$ \\
\hline$-1-$ & 1 & 1 & 0 & 0 \\
\hline$\Rightarrow-1$ & 0 & 0 & 2 & 0 \\
\hline$\longrightarrow$ & 2 & 2 & 0 & 0 \\
\hline$\longrightarrow-C$ & 0 & 0 & 0 & $1(1)$ \\
\hline$-1-1$ & $7(1)$ & $5(1)$ & 8 & $6(1)$ \\
\hline$\longrightarrow$ & $3(3)$ & $3(2)$ & 1 & 0 \\
\hline$-1-2$ & 0 & 0 & 0 & 1 \\
\hline$P$ & 1 & 1 & $1(1)$ & 0 \\
\hline$\rightarrow-7$ & 0 & 0 & 0 & $1(1)$ \\
\hline-2 & $2(2)$ & $1(1)$ & $4(1)$ & $4(1)$ \\
\hline$-1-2$ & $2(1)$ & $2(1)$ & $1(1)$ & 2 \\
\hline$-2-c-1$ & $5(1)$ & 6 & 5 & $7(1)$ \\
\hline$-1-2$ & 3 & 4 & $5(2)$ & 2 \\
\hline$--5-1$ & 0 & 0 & 0 & 0 \\
\hline$-1-c$ & 0 & 0 & $1(1)$ & 0 \\
\hline$-x-1=$ & 0 & 1 & 0 & 0 \\
\hline$-2-2-2-$ & 4 & 1 & 7 & $11(4)$ \\
\hline$--2-2-$ & 1 & 1 & 0 & 0 \\
\hline$\longrightarrow-$ & 0 & 0 & 1 & 0 \\
\hline$\longrightarrow$ & 0 & 0 & 0 & $1(1)$ \\
\hline$-\mathrm{C}-\mathrm{C}-\mathrm{C}$ & 0 & 0 & $1(1)$ & $1(1)$ \\
\hline$-2-2-2-1$ & 1 & 1 & 1 & 0 \\
\hline$-2-2-2-2$ & $1(1)$ & $1(1)$ & 0 & 0 \\
\hline$-2-2-2$ & $1(1)$ & 3 & 4 & $3(2)$ \\
\hline$-6-2-$ & $1(1)$ & 0 & 0 & 0 \\
\hline$---2-$ & $1(1)$ & 1 & 0 & 0 \\
\hline$-2-2-2$ & 0 & 0 & 1 & 0 \\
\hline$-5-2-b-5$ & 1 & 1 & 0 & 0 \\
\hline
\end{tabular}

*Domain architecture was classified according to the nature and number of input (green) transmitter (purple), receiver (blue) and Hpt (orange) domains tNumbers in brackets indicate HyHK that are found associated with a cognate RR 
whereas the remaining $33 \%$ of $\mathrm{HyHKs}$ exhibit atypical domain architectures with multiple transmitter and receiver domains. Such complex domain architectures are puzzling as they may give rise to complex phosphotransfer pathways within each protein. Secondly, while around $25 \%$ of HyHKs consist solely of transmitter and receiver domains without any input domain, the majority of HyHKs seem to have accumulated multiple sensing domains, with up to 10 sensing domains (including nine tandem repeated HAMP-GAF) in two A. lipoferum 4B and Azospirillum sp. B510 orphan HyHKs (AZOLI_p30171, AZL_c01470).

The existence of multi-domain proteins harbouring several sensing domains suggests their ability to detect a wider range of signals. This was functionally validated by deleting the PAS1 or the PAS2 domains of ArcS of Shewanella oineidensis, a HyHK comprising one extracellular Cache domain, two PAS domains, a transmitter domain and two REC domains [52]; deletion of either the PAS1 or the PAS2 domain did not result in the same mutant phenotype suggesting that signal detection occurs in different ways. The two REC domains may have different roles regarding phosphotransfer route as revealed by in vitro phosphotransfer studies [52]. Altogether, Azospirillum may have adapted to their environment by retaining new combinations of existing domains, a process that eventually contributed to increase the genetic diversity of HyHKs.

\section{Evolutionary origin of Azospirillum HyHKs}

Such diverse combinations of domains in addition with the large number of HyHKs found in Azospirillum genomes prompted us to investigate how this expansion of HyHKs arose. To this end, phylogenetic analysis of the 49 transmitter and 62 REC domains from the $49 \mathrm{HyHKs}$ of A. lipoferum 4B (i.e. a total of 111 domains) has been performed (Fig. 3). First, we showed that transmitter and REC domains found in three A. lipoferum 4B HyHK proteins have no orthologue in the three others Azospirillum strains, indicating that these proteins are specific to $A$. lipoferum $4 \mathrm{~B}$ and may have originated recently in this genus. In contrast, we showed that $33 \mathrm{HyHKs}$ display orthologous transmitter and REC domains, meaning that the association between these domains is more ancient in the Azospirillum genus. More precisely, 15 orthologous $\mathrm{HyHKs}$ are found in the four Azopirillum genomes, and 12 are common to A. lipoferum 4B and Azospirillum sp. B510, which is in accordance with their phylogenetic relationship (Additional file 2: Figure S1). Finally, $13 \mathrm{HyHKs}$ displays domains with different evolutionary origins.

Phylogenies of the transmitter and the REC domains suggested that the expansion of these HyHKs has been driven by horizontal gene transfer (HGT, Fig. 3). In fact, 32 out of 49 transmitter domains

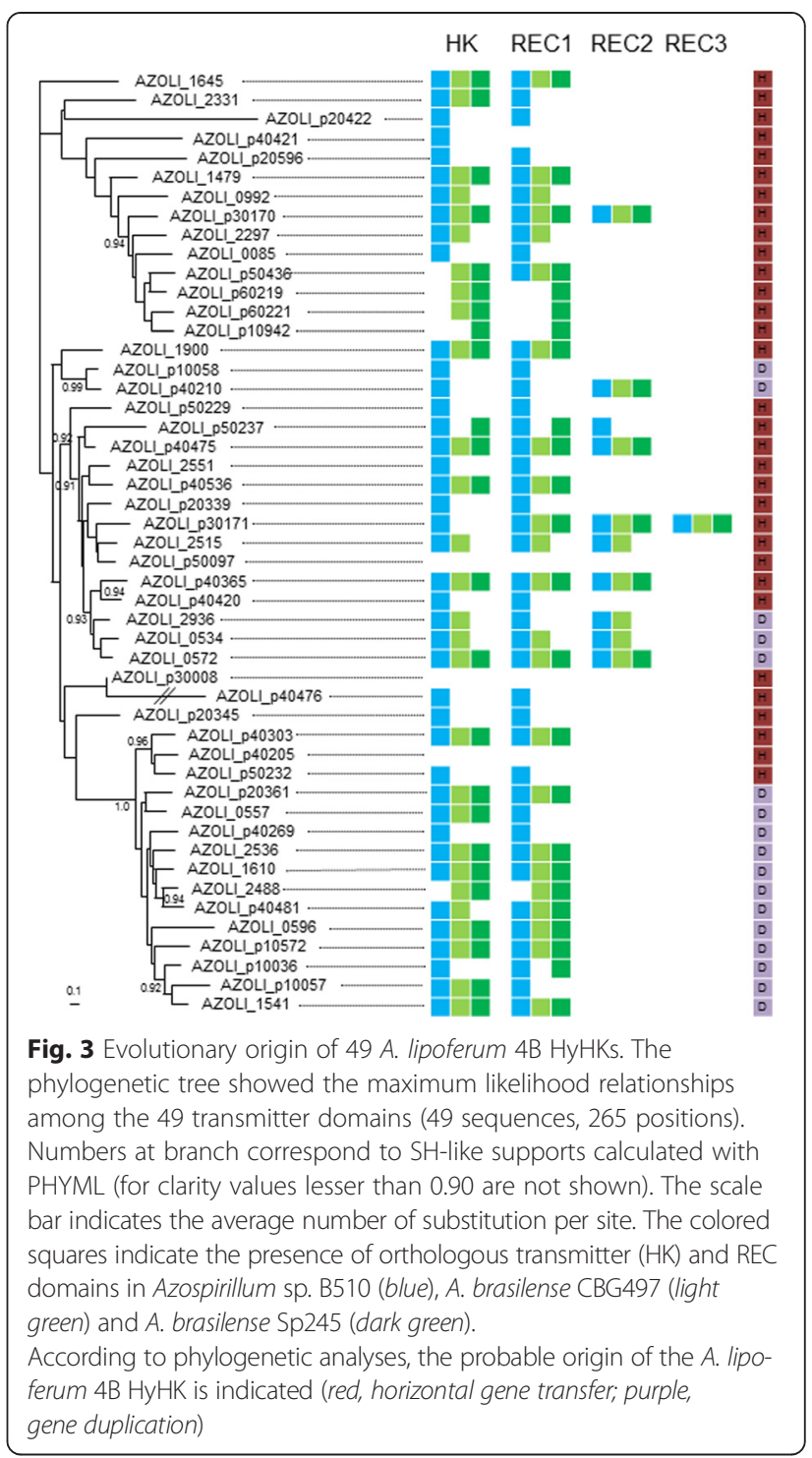

were clustered into clades containing sequences of various bacteria that are not related to Azospirillum (not shown). Although phylogenies of the REC domains were overall less resolved, due to the low number of conserved positions for phylogenetic reconstruction, the same trend could be observed. A clear illustration of such HGT lies in AZOLI_p30008, one HyHK specific to the A. lipoferum species (Fig. 3); indeed, both transmitter and REC domains of AZOLI_p30008 (YP_005040549.1) clustered with several HKs of Methylobacterium (Additional file 2: Figure S2A and S2B). Azospirillum spp. are known for their propensity for genome plasticity [53, 54] and whole-genome analysis revealed that Azospirillum underwent extensive HGT allowing the transition from aquatic to terrestrial environments and association with plants [14]. 
Duplication events also played an important role in the expansion of HyHKs, either at the gene or at the domain level. As such, AZOLI_p10058 (YP_004973569.1) and AZOLI_p40210 (YP_004975186.1) likely originated from the duplication of an ancestral gene that was present in the common ancestor shared by A. lipoferum $4 \mathrm{~B}$ and Azospirillum sp B510 (Fig. 3, Additional file 2: Figure S3A and S3B). Interestingly, the second REC domain found in AZOLI_p40210 has a different origin, being present in the four Azospirillum strains (Fig. 3). This suggested that a domain rearrangement occurred after the duplication event.

Some HyHKs may have also arisen through duplication of a classical HK and fusion with a REC domain of a RR, as previously described [38, 39]; such a scenario has likely occurred for AZOLI_1645, in which the transmitter domain clusters with those of two classical HKs (YP_003448836.1 and YP_005031706.1) and the REC domain grouping with that of a RR (YP_003452077.1) (data not shown). Finally, some HyHKs could have resulted from more complex scenarios involving both HGT and duplication events, as in the case of the transmitter domain and the two REC domains of AZOLI_2936 (data not shown).

In summary, the evolutionary history of HyHKs in $A$. lipoferum $4 \mathrm{~B}$ is complex, involving HGT (mainly from proteobacteria), duplications events as well as recombination events allowing domain shuffling. Domain shuffling often goes hand in hand with lineage specific extension (LSE), and LSE genes are much more likely to be present as orphans as depicted above [30]. Genomewide phylogenetic distribution analysis of $\mathrm{HKs}$ across 207 prokaryotic genomes revealed than more than $70 \%$ of recent duplications displayed an input domain structure different from that of their closest paralogue [30]. Azospirillum HyHKs might have evolved by lateral recruitment of additional sensing domains, thus enabling the detection of a large panel of signals [39]. Altogether, this suggests that the expansion of the HyHK family in Azospirillum may have arisen in response to unique challenges that members of this genus faced.

\section{Diversity of output domains of Azospirillum RRs}

Contrarily to HK transmitter domains, classification of RRs based on sequence similarity cannot help fully determine a putative biological function. However, classification of RRs based on output domain and architecture has been proven to be useful to decipher putative RR functions [55]. Therefore, Azospirillum RRs were classified according to their output domains as shown in Table 5. Firstly, CheY-like RRs containing standalone REC domains and lacking an output domain were found to be overrepresented among
Azospirillum TCS (mean of 32 genes, i.e. $38.7 \pm 1.2 \%$ of total RRs). In comparison, genes encoding RRs consisting of solely a REC domain represent respectively $10.1 \%$ and $13.8 \%$ of $P$. protegens CHA0 and $P$. fluorescens SBW25 total RRs (data not shown). Those genes represent nearly one third of total RRs encoded within the $R$. leguminosarum bv. trifolii WSM 1325 genome, while they represent $23.3 \%$ of $R$. tropici CIAT 899 total RRs. Intriguingly, overrepresentation of RRs with standalone REC domains was found in $N$. punctiforme and $M$. xanthus that respectively represent $36 \%$ and $34 \%$ of the total of their RRs [18, 33]. CheY-type RRs was first described in chemotaxis regulation in $E$. coli, but their roles go far beyond as they can also act as connectors between TCS partners thereby facilitating crosstalk, feedback, and phosphorelays within the two-component phosphorylation network [56]. Interestingly, only A. brasilense Sp245 genome harbours one gene encoding a FrzZ-like RR (AZOBR_p330125), that consists of two REC domains arranged in tandem. In $M$. xanthus, FrzZ was shown to act as a major RR of the chemotaxis system, controlling cell motility and fruiting body formation [57]. Surprisingly, our previous transcriptional analyses of A. lipoferum $4 \mathrm{~B}$ interacting with rice roots revealed that CheY-like standalone RRs were all differentially expressed, strongly suggesting that they may be involved in Azospirillum-plant interaction [58]. However, the exact role played by these single domain RRs needs further investigation.

While most of Azospirillum RRs with known output domains $(64 \% \pm 1 \%)$ contain a DNA-binding domain (39\% $\% 2 \%$ ) and may serve as transcriptional regulators, no RNA-binding domain was detected among Azospirillum RRs, suggesting that no control of gene expression through antitermination is mediated by RRs. Furthermore, enzymatic output domains are common among RRs as $17 \%( \pm 1)$ of them are involved in the modulation of the secondary messenger c-di-GMP or Ser/Thr phosphorylation, suggesting interconnection of Azospirillum TCS with other signal transduction pathways.

\section{Evolutionary conserved TCS and accessory TCS}

The most probable set of orthologous TCS proteins shared by the four Azospirillum strains was identified based on a reciprocal best BLAST hit criterion, as previously described [15]. A total of 123 putative TCS proteins were found to be common to all genomes, thus representing half of Azospirillum TCS gene content (Fig. 4; Additional 3: Table S2; Additional file 4: Table S3; Additional file 5: Table S4; and Additional file 6: Table S5). This core set of Azospirillum TCS comprises 36 HKs, 13 HyHKs and 71 RRs (Fig. 4). Among the 
Table 5 Output domains of Azospirillum RRs

\begin{tabular}{|c|c|c|c|c|c|}
\hline Output domain & RR family & A. lipoferum 4B & Azospirillum sp. B510 & A. brasilense Sp245 & A. brasilense CBG497 \\
\hline \multirow[t]{2}{*}{ Stand-alone REC } & CheY & 39 & 37 & 42 & 36 \\
\hline & FrzZ & - & - & 1 & - \\
\hline \multirow[t]{6}{*}{ DNA-binding } & NarL & 22 & 21 & 22 & 16 \\
\hline & $\mathrm{NtrC}$ & 8 & 10 & 8 & 8 \\
\hline & OmpR & 19 & 27 & 19 & 16 \\
\hline & LytTR & 2 & 2 & 1 & 1 \\
\hline & PrrA & 2 & 2 & 3 & 3 \\
\hline & MarR & - & 1 & 2 & - \\
\hline \multirow[t]{3}{*}{ Chemotaxis } & CheB & 5 & 6 & 4 & 4 \\
\hline & CheY & 5 & 6 & 4 & 4 \\
\hline & CheV & - & - & - & - \\
\hline RNA-binding & AmiR-NasR & - & - & - & - \\
\hline \multirow[t]{4}{*}{ c-di-GMP signalling } & RpfG & 5 & 4 & 3 & 4 \\
\hline & VieA & - & - & - & - \\
\hline & PleD & 7 & 5 & 6 & 5 \\
\hline & PleD-VieA & 1 & 1 & 0 & - \\
\hline Ser/Thr phosphorylation & RsbU & 4 & 3 & 4 & 4 \\
\hline \multirow[t]{2}{*}{ Unknown } & Unclassified & 2 & 7 & 5 & 10 \\
\hline & Total & 121 & 132 & 124 & 111 \\
\hline
\end{tabular}

orthologous TCS genes, 29 TCS pairs were shared by the four Azospirillum strains, including 19 pairs displaying synteny over at least five genes, therefore reflecting possible co-evolution between these cognate HKs and RRs [29, 38]. These TCS may play important roles in regulating general functions common to all strains such as cell growth mechanisms and/or survival in the soil and the rhizosphere ecosystems, and a few of them are discussed hereafter (Table 6). A tetrad of TCS genes is conserved among the four Azospirillum strains and encodes the global nitrogen regulatory system NtrBC and NtrXY, shown to control the transcription of genes involved in nitrogen fixation and assimilation under nitrogen-limitation (Table 6) [59, 60]. The KdpD/ $\mathrm{KdpE}$ system is also common to all strains; in Sinorhizobium meliloti, this system controls the expression of the $k d p A B C$ operon encoding a potassium uptake pump and was shown to play a key role in potassium osmoadaptation and symbiotic performance [61]. Accordingly, genes encoding the putative $\mathrm{KdpABC}$ pump were also present within Azospirillum genomes forming a putative operon with $k d p D$ and $k d p E$ (Table 6). The Kdp system has been shown to be crucial in the regulation of many hostpathogen interaction mechanisms, promoting bacterial virulence and resistance against various stresses [62]. Therefore, the Azospirillum $\mathrm{KdpD} / \mathrm{KdpE}$ system may confer an adaptive advantage to Azospirillum in the rhizosphere.
TCS sharing similarity with the PhoB/PhoR signal transduction system were also retrieved from all Azospirillum genomes, adjacent to the pstSCAB-phoU operon encoding an $A B C$ transporter important for the high-affinity capture of periplasmic inorganic phosphate (Table 6) [63]. Under low inorganic phosphate concentration, $\mathrm{PhoB} /$ PhoR activates the pstSCAB-phoU operon [63]. Moreover, a link between the regulation of phosphate metabolism and biofilm formation has been highlighted in some rhizobacteria, as expression of the Pho regulon was shown to affect biofilm formation in P. fluorescens [64].

Homologues of the $\operatorname{ch} v G / \operatorname{ch} v I$ genes are also present in the four Azospirillum genomes (Table 6). This TCS is highly conserved among free-living alphaproteobacteria where it controls many processes involved in successful host-bacteria interaction. Indeed, ChvGI regulates the expression of virulence gene expression in response to acidic conditions in the plant pathogen Agrobacterium tumefaciens [65] whereas in S. meliloti ExoS, an orthologue of ChvG, positively regulates succinoglycan synthesis (thereby promoting biofilm formation) and prevents flagellum biosynthesis [66]. However, to our knowledge whether this TCS in Azospirillum plays a role in the plant-bacteria interaction has never been elucidated.

Interestingly, one Azospirillum TCS belongs to the family of LytS/LytR TCS, shown to be involved in the regulation of bacterial virulence genes (Table 6) [67]. Based on sequence analyses, the LytS-like $\mathrm{HK}$ is 


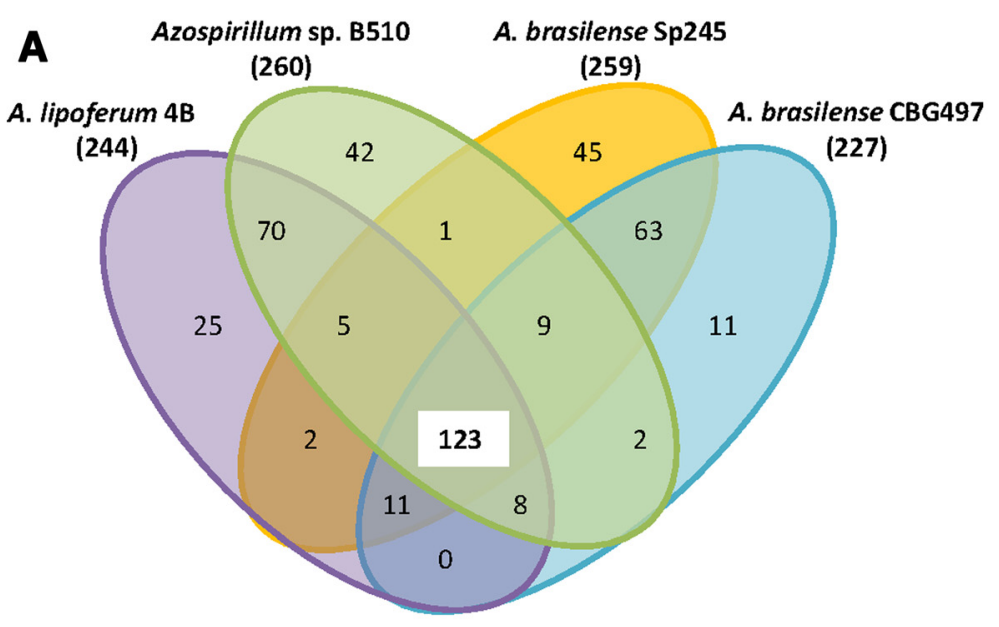

B Azospirillum sp. B510

A. brasilense Sp245

(47)

(55)

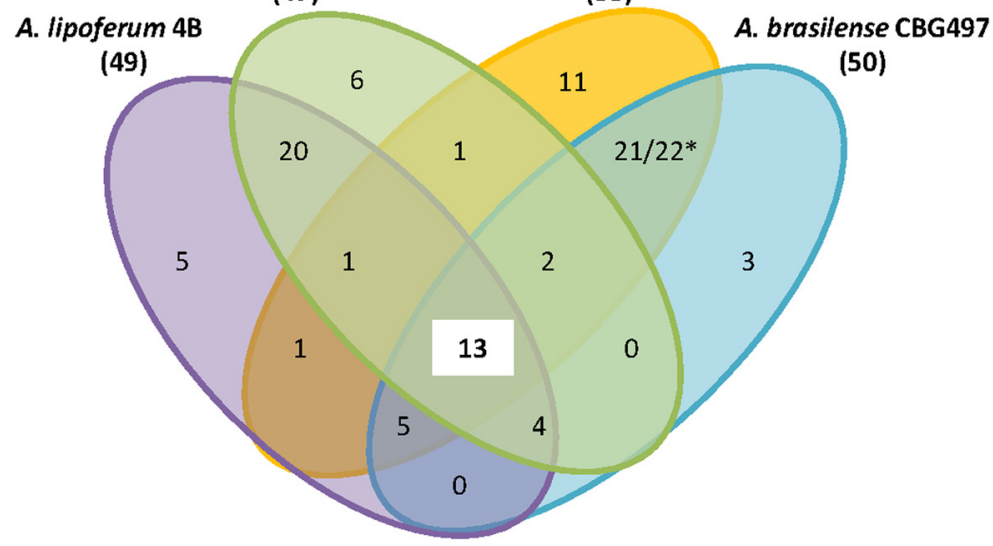

Fig. 4 Venn diagrams representing numbers of orthologous and unique TCS genes between and among the four Azospirillum strains studied. a Numbers of orthologous total TCS genes; b Numbers of orthologous genes encoding HyHKs. The number of orthologous TCS genes was determined by reciprocal best blast hit (amino acid identity percentage greater than $35 \%$ and query coverage greater than $75 \%$ ). The total number of TCS coding genes within each genome is listed in brackets next to the strain name. * Among HyHKs common to both A. brasilense strains, 21 were classified as HyHKs in A. brasilense Sp245 and 22 in A. brasilense CBG497

predicted to be a membrane-bound sensor, and the LytR-like RR is predicted to contain a CheY-like REC domain and a DNA-binding domain (PF04397), as expected. The analysis of the genetic context of the LytS/LytR-like genes in Azospirillum showed a genetic link with genes encoding a putative multidrug resistance efflux pump. To our knowledge, whether the LytS/LytR-like in Azospirillum is functionally coupled to the regulation of the adjacent efflux pump has never been investigated.

However, there are differences in TCS proteins among the four Azospirillum strains that may contribute to niche-specific adaptation. The number of strain-specific TCS genes varies greatly among the four genomes (Fig. 4; Additional 3: Table S2; Additional file 4: Table S3; Additional file 5: Table S4; and Additional file 6: Table $\mathrm{S} 5)$. For the vast majority of these unique TCS genes, making functional correlations seems hazardous but several unique TCS genes of $A$. lipoferum 4B caught our attention. In this strain, the five first genes of the TCS hexad, spanning from AZOLI_0973 to AZOLI_0977, had no putative homologue in the three other strains. Similarity searches of these genes revealed significant matches with non-contiguous TCS genes of $M$. magneticum, except for AZOLI_0976 which encodes an atypical RR (REC-PAS-GGDEF) showing a significant identity (41 \%) over the PAS and GGDEF domains with a protein from psychrophile Colwellia psychrerythraea belonging to the gammaproteobacteria lineage (Additional file 3: Table S2). Two explanations can be proposed to explain these observations. First, the presence of these five genes in A. lipoferum 4B and M. magneticum may result from HGT between these two strains, or alternatively, they may have been present in the common ancestor shared 
Table 6 Azospirillum TCS orthologues with inferred biological functions

\begin{tabular}{|c|c|c|c|c|c|}
\hline Gene $^{a}$ & Label $^{b}$ & $\mathrm{BBH}\left(\%\right.$ amino acid identity) ${ }^{\mathrm{C}}$ & Putative functions & Relevant feature & References \\
\hline $\begin{array}{l}\text { chvG } \\
\text { chvl }\end{array}$ & $\begin{array}{l}\text { AZOLI_2965 } \\
\text { AZOLI_2966 }\end{array}$ & $\begin{array}{l}\text { Rhodospirillum centenum (60 \%) } \\
\text { Rhodospirillum centenum (84 \%) }\end{array}$ & $\begin{array}{l}\text { Virulence and TVISS regulation in A. tumefaciens } \\
\text { Biofilm and motility in S. meliloti }\end{array}$ & $\begin{array}{l}\text { Conserved in members } \\
\text { of the a-proteobacteria }\end{array}$ & {$[68][66]$} \\
\hline $\begin{array}{l}\text { phoR } \\
\text { phoB }\end{array}$ & $\begin{array}{l}\text { AZOLI_3010 } \\
\text { AZOLI_3109 }\end{array}$ & $\begin{array}{l}\text { Rhodospirillum centenum ( } 54 \% \text { ) } \\
\text { Rhodopseudomonas palustris } \\
\text { (65\%) }\end{array}$ & $\begin{array}{l}\text { Virulence and survival in Vibrio cholerae Biofilm } \\
\text { formation in P. fluorescens }\end{array}$ & $\begin{array}{l}\text { phoB located upstream } \\
\text { a putative pst } A B C \\
\text { transporter }\end{array}$ & [69] [64] \\
\hline $\begin{array}{l}d c t B \\
d c t D\end{array}$ & $\begin{array}{l}\text { AZOLI_p10629 } \\
\text { AZOLI_p10628 }\end{array}$ & $\begin{array}{l}\text { Arhodomonas aquaeolei (60 \%) } \\
\text { Pseudomonas fuscovaginae } \\
(43 \%)\end{array}$ & $\begin{array}{l}\text { Root colonization and beneficial properties in } \\
\text { P. chlororaphis C4-dicarboxylate transport and } \\
\text { nitrogen fixation in rhizobia }\end{array}$ & $\begin{array}{l}\text { Located upstream of a } \\
\text { putative } d c t A \\
\text { transporter }\end{array}$ & {$[70][71]$} \\
\hline $\begin{array}{l}n \operatorname{tr} B \\
n \operatorname{trC} C\end{array}$ & $\begin{array}{l}\text { AZOLI_1342 } \\
\text { AZOLI_1343 }\end{array}$ & $\begin{array}{l}\text { Rhodospirillum centenum (73\%) } \\
\text { Rhodospirillum centenum (83\%) }\end{array}$ & $\begin{array}{l}\text { Regulation of nitrogen metabolism, nitrate } \\
\text { utilization and ammonium transport }\end{array}$ & Clustered with ntrXY & [59] \\
\hline $\begin{array}{l}n+r X \\
n t r Y\end{array}$ & $\begin{array}{l}\text { AZOLI_1344 } \\
\text { AZOLI_1345 }\end{array}$ & $\begin{array}{l}\text { Rhodospirillum centenum (62 \%) } \\
\text { Rhodospirillum centenum (83\%) }\end{array}$ & $\begin{array}{l}\text { Regulation of nitrogen metabolism, nitrate } \\
\text { utilization and ammonium transport }\end{array}$ & Clustered with $n t r B C$ & {$[60]$} \\
\hline $\begin{array}{l}k d p D \\
k d p E\end{array}$ & $\begin{array}{l}\text { AZOLI_p20517 } \\
\text { AZOLI_p20518 }\end{array}$ & $\begin{array}{l}\text { Pseudaminobacter salicylatoxidans } \\
\text { (76\%) Rhodospirillum bacterium } \\
\text { URHD0088 (64 \%) }\end{array}$ & $\begin{array}{l}\text { Potassium transport and virulence in S. aureus } \\
\text { Osmoadaptation and symbiosis in S. meliloti }\end{array}$ & $\begin{array}{l}\text { Located next to } k d p A B C \\
\text { encoding a potassium } \\
\text { pump }\end{array}$ & {$[72][61]$} \\
\hline $\begin{array}{l}\text { lyts } \\
\text { lytR }\end{array}$ & $\begin{array}{l}\text { AZOLI_p50421 } \\
\text { AZOLI_p50422 }\end{array}$ & $\begin{array}{l}\text { Rhodospirillum rubrum (74 \%) } \\
\text { Rhodospirillum rubrum (73\%) }\end{array}$ & $\begin{array}{l}\text { Carbon control network in E. coli Virulence in } S . \\
\text { aureus }\end{array}$ & $\begin{array}{l}\text { Located next to genes } \\
\text { encoding a putative } \\
\text { MDR efflux pump }\end{array}$ & {$[73][67]$} \\
\hline$f l C A$ & AZOLI_1403 & Rhodospirillum centenum (65 \%) & Flocculation and root colonization in A. brasilense & Orphan RR & [74] \\
\hline bphP1 & AZOLI_p20424 & $\begin{array}{l}\text { Stenotrophomonas maltophilia } \\
(53 \%)\end{array}$ & Light-stress tolerance and motility in A. brasilense & $\begin{array}{l}\text { Organized in a triad of } \\
\text { TCS (HyHK-RR-Bph1) }\end{array}$ & [48] \\
\hline
\end{tabular}

${ }^{\mathrm{a}}$ For each pair, the first gene encodes the HK whereas the second gene encodes the RR

bLabels refer to genes of $A$. lipoferum 4B. Labels of the orthologues of other Azospirillum strains can be found in Additional file 3: Table S2; Additional file 4: Table S3; Additional file 5: Table S4 and Additional file 6: Table S5

${ }^{\mathrm{C}} \mathrm{A}$. lipoferum $\mathrm{BB}$ amino acid sequences were used as queries

by these two strains, and secondarily lost in the three others Azospirillum strains and in Rhodospirillum centenum SW in agreement with the phylogeny of species (Additional file 2: Figure S1). As for the proteins encoded by AZOLI_p10944 and AZOLI_p10945, they exhibit homology to the MoxYX system of Starkeya novella, a facultative chemolithoautotrophic and methylotrophic alphaproteobacterium (Additional file 3: Table S2). Synteny analysis between these two genomic regions revealed strong conservation of the $\operatorname{mox} X Y$ genes forming a putative operon with moxFJGIR, thus suggesting that MoxYX might control A. lipoferum 4B methanol metabolism. Interestingly, A. lipoferum $4 \mathrm{~B}$ was shown to grow slightly with methanol as sole carbon source (Our unpublished data). Therefore, tight regulation of this metabolic versatility may be relevant in specific environments such as rice paddy fields, from which A. lipoferum 4B was isolated.

\section{Conclusions}

In summary, here we provide evidence of the incredible complexity of Azospirillum TCS regulatory networks. The existence of large numbers of TCS and especially HyHKs reinforces the idea that these genes can support traits needed for thriving in heterogeneous, fluctuating and highly competitive environments, such as the rhizosphere. Our phylogenetic analyses indicate that the expansion of the HyHK family in Azospirillum has occurred mainly through HGT, even if gene duplication and domain shuffling also played an important role. We further gained insights into the core of orthologues TCS proteins and differences between TCS repertoire of the four strains that are likely to facilitate Azospirillum adaptation to different host plants. Future studies focused on the functional analysis of these TCS might shed light on the complex events occurring during Azospirillum soil survival and plant growth-promotion in different environmental settings. Ultimately, focusing on mechanisms by which beneficial plant-associated bacteria persist and compete in soil would be useful for improving plant growth-promotion strategies.

\section{Additional files}

Additional file 1: Table S1. Complete list of genomes surveyed during this study. (XLSX $153 \mathrm{~kb}$ )

Additional file 2: Figure S1. Distance-based phylogenetic tree showing the relationships among the different organisms being considered in this study. The phylogeny was derived from concatenated alignments of the ribosomal proteins L3, L5, L11, L13, L14, S3, S7, S9, S11, and S17. Numbers at branch correspond to bootstrap values (1,000 replicates of the original alignment). Branch lengths are proportional to the number of substitutions per site (see the scale bar). Blue boxes highlight alpha-proteobacterial sequences that are closely related to that of $A$. lipoferum (represented in blue). Figure S2. Phylogenies of the transmitter and REC domain of AZOLI_p30008. Maximum Likelihood trees of the transmitter (A) and REC (B) domains of the AZOLI_p30008 (153 and 83 amino acid 
positions, respectively). Numbers at branch correspond to $\mathrm{SH}$-like supports calculated with PHYML (for clarity values lesser than 0.90 are not shown). The scale bars indicate the average number of substitution per site. Colours correspond to taxonomic groups: Orange: A. lipoferum 4B, light blue: Azospirillum sp. B510, light green: A. brasilense CBG497, dark green: A. brasilense Sp245, dark blue: other alphaproteobacteria, light brown: Delta/Epsilonproteobacteria, pink: Betaproteobacteria, dark brown: Gammaproteobacteria, black: other bacteria. The proximity of both domains with sequences from Methylobacteriuym suggests that a horizontal gene transfer event occurred between these two lineages. Figure S3. Phylogenies of the transmitter and REC domains of AZOLI_p10058. Maximum Likelihood trees of the transmitter (A) and REC (B) domains of the AZOLI_p10058 (157 and 90 amino acid positions, respectively). Numbers at branch correspond to SH-like supports calculated with PHYML (for clarity values lesser than 0.90 are not shown). The scale bars indicate the average number of substitution per site. Colours correspond to taxonomic groups: Orange: A. lipoferum 4B, light blue: Azospirillum sp. B510, light green: A. brasilense CBG497, dark green: A. brasilense Sp245, dark blue: other alphaproteobacteria, light brown: Delta/Epsilonproteobacteria, pink: Betaproteobacteria, dark brown: Gammaproteobacteria, black: other bacteria. A duplication event leading to Azospirillum sp. B510 YP_003452479 and A. lipoferum 4B YP_004975186 on the one hand, and to Azospirillum sp. B510 YP_003450084 and A. lipoferum 4B YP_004973569 on the other hand is visible on both trees. (PPT $820 \mathrm{~kb}$ )

Additional file 3: Table S2. Domain architecture, genetic organization and subcellular localization of A. lipoferum 4B TCS components. (XLSX $40 \mathrm{~kb}$ )

Additional file 4: Table S3. Domain architecture, genetic organization and subcellular localization of Azospirillum sp. B510 TCS components. (XLSX $72 \mathrm{~kb}$ )

Additional file 5: Table S4. Domain architecture, genetic organization and subcellular localization of A. brasilense Sp245 TCS components. (XLSX $33 \mathrm{~kb}$ )

Additional file 6: Table S5. Domain architecture, genetic organization and subcellular localization of $A$. brasilense CBG497 TCS components. (XLSX $28 \mathrm{~kb})$

\section{Abbreviations}

TCS: Two-component systems; HK: Histidine kinase; HyHK: Hybrid histidine kinase; LSE: Lineage specific expansion; REC: Receiver domain; RR: Response regulator.

\section{Competing interests}

The authors declare that they have no competing interest.

\section{Authors' contributions}

SB and FWD designed the study. FWD and CPC coordinated the study. SB performed the analyses, except for the phylogenetic analyses of HyHKs that was conducted by $\mathrm{AO}$ and $\mathrm{CBA}$. SB drafted the manuscript that was subsequently revised by all co-authors. All authors read and approved the final manuscript.

\section{Author's Information}

Not Applicable.

\section{Availability of data and materials}

Not Applicable.

\section{Acknowledgements}

We are grateful to Audrey Dubost (iBio platform of UMR-CNRS 5557) for her great help. SB received a fellowship from « Ministère de l'enseignement supérieur et de la recherche ». AO was the recipient of a grant from the "Ancestrome" project (ANR-10-BINF-01-01). CBA is a member of the Institut Universitaire de France and funded by the "Ancestrome" project. This work has been performed using the computing facilities of the CC LBBE/PRABI.

\section{Author details}

'Université de Lyon, Université Lyon 1, CNRS, UMR5557, Laboratoire d'Ecologie Microbienne, 437 boulevard du 11 novembre 1918, F-69622 Villeurbanne, France. ${ }^{2}$ Université de Lyon, Université Lyon 1, CNRS, UMR5558, Laboratoire de Biométrie et Biologie Evolutive, 43 boulevard du 11 novembre 1918, F-69622 Villeurbanne, France.

\section{Received: 24 June 2015 Accepted: 29 September 2015} Published online: 22 October 2015

\section{References}

1. Berendsen RL, Pieterse CMJ, Bakker PAHM. The rhizosphere microbiome and plant health. Trends Plant Sci. 2012;17:478-86.

2. Hinsinger P, Gobran GR, Gregory PJ, Wenzel WW. Rhizosphere geometry and heterogeneity arising from root-mediated physical and chemical processes. New Phytol. 2005;168:293-303.

3. Gao R, Stock AM. Biological insights from structures of two-component proteins. Annu Rev Microbiol. 2009;63:133-54.

4. Appleby JL, Parkinson JS, Bourret RB. Signal transduction via the multi-step phosphorelay: not necessarily a road less traveled. Cell. 1996;86:845-8.

5. Galperin MY. A census of membrane-bound and intracellular signal transduction proteins in bacteria: Bacterial IQ, extroverts and introverts. BMC Microbiol. 2005;5:35

6. Ulrich LE, Koonin EV, Zhulin IB. One-component systems dominate signal transduction in prokaryotes. Trends Microbiol. 2005;13:52-6.

7. Lavín JL, Kiil K, Resano O, Ussery DW, Oguiza JA. Comparative genomic analysis of two-component regulatory proteins in Pseudomonas syringae. BMC Genomics. 2007;8:397.

8. Zhao Y, Wang D, Nakka S, Sundin GW, Korban SS. Systems level analysis of two-component signal transduction systems in Erwinia amylovora: Role in virulence, regulation of amylovoran biosynthesis and swarming motility. BMC Genomics. 2009;10:245.

9. Vacheron J, Desbrosses G, Bouffaud M-L, Touraine B, Moenne-Loccoz Y, Muller D, Legendre L, Wisniewski-Dye F, Prigent-Combaret C: Plant growthpromoting rhizobacteria and root system functioning. Front Plant Sci 2013;356:4. doi:10.3389/fpls.2013.00356.

10. Wisniewski-Dyé F, Drogue B, Borland S, Prigent-Combaret C: Azospirillumplant interaction: from root colonization to plant growth promotion. In Beneficial plant-microbial interactions: ecology and applications. Boca Raton, FL, USA: CRC Press. 2013;237-69.

11. Bashan Y, Holguin G, De-Bashan LE. Azospirillum-plant relationships: physiological, molecular, agricultural, and environmental advances (1997-2003). Can J Microbiol. 2004;50:521-77.

12. Drogue $B$, Doré $H$, Borland $S$, Wisniewski-Dyé F, Prigent-Combaret C. Which specificity in cooperation between phytostimulating rhizobacteria and plants? Res Microbiol. 2012;163:500-10.

13. Chamam A, Sanguin H, Bellvert F, Meiffren G, Comte G, Wisniewski-Dyé F, et al. Plant secondary metabolite profiling evidences strain-dependent effect in the Azospirillum-Oryza sativa association. Phytochemistry. 2013:87:65-77.

14. Wisniewski-Dyé F, Borziak K, Khalsa-Moyers G, Alexandre G, Sukharnikov LO,

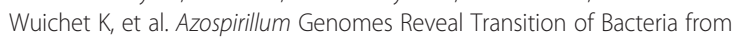
Aquatic to Terrestrial Environments. PLoS Genet. 2011;7:e1002430.

15. Wisniewski-Dyé F, Lozano L, Acosta-Cruz E, Borland S, Drogue B, Prigent-Combaret $C$, et al. Genome Sequence of Azospirillum brasilense CBG497 and Comparative Analyses of Azospirillum Core and Accessory Genomes provide Insight into Niche Adaptation. Genes. 2012;3:576-602.

16. Vallenet D, Labarre L, Rouy Z, Barbe V, Bocs S, Cruveiller S, et al. MaGe: a microbial genome annotation system supported by synteny results. Nucleic Acids Res. 2006;34:53-65

17. Barakat M, Ortet $P$, Jourlin-Castelli C, Ansaldi M, Méjean V, Whitworth DE. P2CS: a two-component system resource for prokaryotic signal transduction research. BMC Genomics. 2009;10:315.

18. Whitworth DE, Cock PJA. Two-component systems of the myxobacteria: structure, diversity and evolutionary relationships. Microbiology. 2008;154:360-72.

19. Li W, Godzik A. Cd-hit: a fast program for clustering and comparing large sets of protein or nucleotide sequences. Bioinformatics. 2006:22:1658-9.

20. Sievers F, Wilm A, Dineen D, Gibson TJ, Karplus K, Li W, et al. Fast, scalable generation of high-quality protein multiple sequence alignments using Clustal Omega. Mol Syst Biol. 2011;7:539. 
21. Castresana J. Selection of conserved blocks from multiple alignments for their use in phylogenetic analysis. Mol Biol Evol. 2000;17:540-52.

22. Gouy M, Guindon S, Gascuel O. SeaView Version 4: A Multiplatform Graphical User Interface for Sequence Alignment and Phylogenetic Tree Building. Mol Biol Evol. 2010;27:221-4

23. Altschul SF, Madden TL, Schäffer AA, Zhang J, Zhang Z, Miller W, et al. Gapped BLAST and PSI-BLAST: a new generation of protein database search programs. Nucleic Acids Res. 1997;25:3389-402

24. Katoh K, Misawa K, Kuma K, Miyata T. MAFFT: a novel method for rapid multiple sequence alignment based on fast Fourier transform. Nucleic Acids Res. 2002;30:3059-66.

25. Guindon S, Dufayard J-F, Lefort V, Anisimova M, Hordijk W, Gascuel O. New algorithms and methods to estimate maximum-likelihood phylogenies: assessing the performance of PhyML 3.0. Syst Biol. 2010;59:307-21.

26. Le SQ, Gascuel O. An Improved General Amino Acid Replacement Matrix Mol Biol Evol. 2008;25:1307-20.

27. Kaneko T, Minamisawa $K$, Isawa T, Nakatsukasa H, Mitsui H, Kawaharada $Y$, et al. Complete Genomic Structure of the Cultivated Rice Endophyte Azospirillum sp. B510. DNA Res. 2010;17:37-50.

28. Mizuno T. Compilation of all genes encoding two-component phosphotransfer signal transducers in the genome of Escherichia coli. DNA Res. 1997;4:161-8.

29. Koretke KK, Lupas AN, Warren PV, Rosenberg M, Brown JR. Evolution of two-component signal transduction. Mol Biol Evol. 2000;17:1956-70.

30. Alm E, Huang K, Arkin A. The Evolution of Two-Component Systems in Bacteria Reveals Different Strategies for Niche Adaptation. PLoS Comput Biol. 2006;2:e143.

31. Fabret C, Feher VA, Hoch JA. Two-Component Signal Transduction in Bacillus subtilis: How One Organism Sees Its World. J Bacteriol. 1999;181:1975-83.

32. Galperin MY, Higdon R, Kolker E. Interplay of heritage and habitat in the distribution of bacterial signal transduction systems. Mol Biosyst. 2010;6:721-8

33. Ashby MK, Houmard J. Cyanobacterial Two-Component Proteins: Structure, Diversity, Distribution, and Evolution. Microbiol Mol Biol Rev. 2006;70:472-509.

34. Sirota-Madi A, Olender T, Helman Y, Ingham C, Brainis I, Roth D, et al. Genome sequence of the pattern forming Paenibacillus vortex bacterium reveals potential for thriving in complex environments. BMC Genomics. 2010;11:710

35. Sadasivan L, Neyra CA. Flocculation in Azospirillum brasilense and Azospirillum lipoferum: exopolysaccharides and cyst formation. J Bacteriol. 1985;163:716-23.

36. Nakazawa H, Arakaki A, Narita-Yamada S, Yashiro I, Jinno K, Aoki N, et al. Whole genome sequence of Desulfovibrio magneticus strain RS-1 revealed common gene clusters in magnetotactic bacteria. Genome Res. 2009:19:1801-8.

37. Williams RH, Whitworth DE. The genetic organisation of prokaryotic twocomponent system signalling pathways. BMC Genomics. 2010;11:720.

38. Whitworth DE, Cock PJA. Evolution of prokaryotic two-component systems: insights from comparative genomics. Amino Acids. 2009;37:459-66.

39. Zhang W, Shi L. Distribution and evolution of multiple-step phosphorelay in prokaryotes: lateral domain recruitment involved in the formation of hybridtype histidine kinases. Microbiology. 2005;15:2159-73.

40. Wise AA, Fang F, Lin Y-H, He F, Lynn DG, Binns AN. The Receiver Domain of Hybrid Histidine Kinase VirA: an Enhancing Factor for vir Gene Expression in Agrobacterium tumefaciens. J Bacteriol. 2010;192:1534-42.

41. Cock PJA, Whitworth DE. Evolution of prokaryotic two-component system signaling pathways: gene fusions and fissions. Mol Biol Evol. 2007:24:2355-7.

42. Cheung J, Hendrickson WA. Sensor domains of two-component regulatory systems. Curr Opin Microbiol. 2010;13:116-23.

43. Buelow DR, Raivio TL. Three (and more) component regulatory systems auxiliary regulators of bacterial histidine kinases. Mol Microbiol. 2010;75:547-66.

44. Taylor BL, Zhulin IB. PAS domains: internal sensors of oxygen, redox potential, and light. Microbiol Mol Biol Rev. 1999;63:479-506.

45. Henry JT, Crosson S. Ligand-Binding PAS Domains in a Genomic, Cellular, and Structural Context. Annu Rev Microbiol. 2011;65:261-86.

46. Aravind $\mathrm{L}$, Ponting $\mathrm{CP}$. The cytoplasmic helical linker domain of receptor histidine kinase and methyl-accepting proteins is common to many prokaryotic signalling proteins. FEMS Microbiol Lett. 1999:176:111-6.

47. Bhoo S-H, Davis SJ, Walker J, Karniol B, Vierstra RD. Bacteriophytochromes are photochromic histidine kinases using a biliverdin chromophore. Nature 2001;414:776-9.
48. Kumar S, Kateriya S, Singh VS, Tanwar M, Agarwal S, Singh H, Khurana JP, Amla DV, Tripathi AK: Bacteriophytochrome controls carotenoid-independent response to photodynamic stress in a non-photosynthetic rhizobacterium, Azospirillum brasilense Sp7. Sci Rep 2012:872:2. doi:10.1038/srep00872.

49. Tam R, Saier MH. Structural, functional, and evolutionary relationships among extracellular solute-binding receptors of bacteria. Microbiol Rev. 1993;57:320-46.

50. Shu CJ, Ulrich LE, Zhulin IB. The NIT domain: a predicted nitrate-responsive module in bacterial sensory receptors. Trends Biochem Sci. 2003;28:121-4.

51. Hegyi H, Gerstein M. Annotation Transfer for Genomics: Measuring Functional Divergence in Multi-Domain Proteins. Genome Res. 2001;11:1632-40.

52. Lassak J, Bubendorfer S, Thormann KM. Domain analysis of ArcS, the hybrid sensor kinase of the Shewanella oneidensis MR-1 Arc two-component system, reveals functional differentiation of its two receiver domains. J Bacteriol. 2013;195:482-92.

53. Vial L, Lavire C, Mavingui P, Blaha D, Haurat J, Moenne-Loccoz Y, et al. Phase Variation and Genomic Architecture Changes in Azospirillum. J Bacteriol. 2006;188:5364-73.

54. Pothier JF, Prigent-Combaret C, Haurat J, Moënne-Loccoz Y, Wisniewski-Dyé F. Duplication of plasmid-borne nitrite reductase gene nirk in the wheatassociated plant growth-promoting rhizobacterium Azospirillum brasilense Sp245. Mol Plant-Microbe Interact. 2008;21:831-42.

55. Galperin MY. Diversity of Structure and Function of Response Regulator Output Domains. Curr Opin Microbiol. 2010;13:150-9.

56. Jenal U, Galperin MY. Single domain response regulators: molecular switches with emerging roles in cell organization and dynamics. Curr Opin Microbiol. 2009;12:152-60.

57. Inclán YF, Vlamakis HC, Zusman DR. FrzZ, a dual CheY-like response regulator, functions as an output for the Frz chemosensory pathway of Myxococcus xanthus. Mol Microbiol. 2007;65:90-102

58. Drogue B, Sanguin H, Borland S, Prigent-Combaret C, Wisniewski-Dyé F. Genome wide profiling of Azospirillum lipoferum 4B gene expression during interaction with rice roots. FEMS Microbiol Ecol. 2014;87:543-55.

59. Liang $Y Y$, Arsène $F$, Elmerich $C$. Characterization of the $n t r B C$ genes of Azospirillum brasilense Sp7: Their involvement in the regulation of nitrogenase synthesis and activity. Mol Gen Genet. 1993;240:188-96.

60. Ishida ML, Assumpção MC, Machado HB, Benelli EM, Souza EM, Pedrosa FO. Identification and characterization of the two-component NtrY/NtrX regulatory system in Azospirillum brasilense. Braz J Med Biol Res. 2002;35:651-61.

61. Domínguez-Ferreras A, Muñoz S, Olivares J, Soto MJ, Sanjuán J. Role of potassium uptake systems in Sinorhizobium meliloti osmoadaptation and symbiotic performance. J Bacteriol. 2009;191:2133-43.

62. Freeman ZN, Dorus S, Waterfield NR. The KdpD/KdpE Two-Component System: Integrating $\mathrm{K}^{+}$Homeostasis and Virulence. PLoS Pathog. 2013;9:e1003201

63. Lamarche MG, Wanner BL, Crépin S, Harel J. The phosphate regulon and bacterial virulence: a regulatory network connecting phosphate homeostasis and pathogenesis. FEMS Microbiol Rev. 2008:32:461-73.

64. Monds RD, Newell PD, Gross RH, O'Toole GA. Phosphate-dependent modulation of c-di-GMP levels regulates Pseudomonas fluorescens PfO-1 biofilm formation by controlling secretion of the adhesin LapA. Mol Microbiol. 2007:63:656-79.

65. Li L, Jia Y, Hou Q, Charles TC, Nester EW, Pan SQ. A global pH sensor: Agrobacterium sensor protein ChvG regulates acid-inducible genes on its two chromosomes and Ti plasmid. Proc Natl Acad Sci. 2002;99:12369-74.

66. Yao S-Y, Luo L, Har KJ, Becker A, Rüberg S, Yu G-Q, et al. Sinorhizobium meliloti ExoR and ExoS proteins regulate both succinoglycan and flagellum production. J Bacteriol. 2004;186:6042-9.

67. Sidote DJ, Barbieri CM, Wu T, Stock AM. Structure of the Staphylococcus aureus AgrA LytTR domain bound to DNA reveals a beta fold with an unusual mode of binding. Struct Lond Engl 1993. 2008;16:727-35.

68. Wu C-F, Lin J-S, Shaw G-C, Lai E-M. Acid-Induced Type VI Secretion System Is Regulated by ExoR-ChvG/Chvl Signaling Cascade in Agrobacterium tumefaciens. PLoS Pathog. 2012;8:e1002938.

69. Pratt JT, Ismail AM, Camilli A. PhoB regulates both environmental and virulence gene expression in Vibrio cholerae. Mol Microbiol. 2010;77:1595-605.

70. Nam HS, Anderson AJ, Yang KY, Cho BH, Kim YC. The dctA gene of Pseudomonas chlororaphis $\mathrm{O} 6$ is under RpoN control and is required for effective root colonization and induction of systemic resistance. FEMS Microbiol Lett. 2006;256:98-104. 
71. Ronson CW, Astwood PM, Downie JA. Molecular cloning and genetic organization of C4-dicarboxylate transport genes from Rhizobium leguminosarum. J Bacteriol. 1984;160:903-9.

72. Xue T, You Y, Hong D, Sun H, Sun B. The Staphylococcus aureus KdpDE Two-Component System Couples Extracellular $\mathrm{K}^{+}$Sensing and Agr Signaling to Infection Programming. Infect Immun. 2011;79:2154-67.

73. Kraxenberger T, Fried L, Behr S, Jung K. First insights into the unexplored two-component system YehU/YehT in Escherichia coli. J Bacteriol. 2012;194:4272-84

74. Pereg-Gerk L, Paquelin A, Gounon P, Kennedy IR, Elmerich C. A transcriptional regulator of the LuxR-UhpA family, FlcA, controls flocculation and wheat root surface colonization by Azospirillum brasilense Sp7. Mol Plant-Microbe Interact. 1998:11:177-87.

\section{Submit your next manuscript to BioMed Central and take full advantage of:}

- Convenient online submission

- Thorough peer review

- No space constraints or color figure charges

- Immediate publication on acceptance

- Inclusion in PubMed, CAS, Scopus and Google Scholar

- Research which is freely available for redistribution 